\title{
Analysis of Water-Cooled Intercooler Thermal Characteristics
}

\author{
Chao $\mathrm{Yu}^{1, *}{ }^{1}$, Wenbao Zhang ${ }^{1}$, Xiangyao Xue ${ }^{1}$, Jiarun Lou ${ }^{1}$ and Guochao Lao ${ }^{2}$ \\ 1 Changchun Institute of Optics, Fine Mechanics and Physics, Chinese Academy of Sciences, \\ Changchun 130033, China; qw417345721@163.com (W.Z.); my691930402@163.com (X.X.); \\ ou910160194@163.com (J.L.) \\ 2 The 96901 Unit of PLA, Beijing 10094, China; laoguochao@mail.sdu.edu.cn \\ * Correspondence: yuchao@ciomp.ac.cn
}

Citation: Yu, C.; Zhang, W.; Xue, X.; Lou, J.; Lao, G. Analysis of Water-Cooled Intercooler Thermal Characteristics. Energies 2021, 14, 8332. https://doi.org/10.3390/ en14248332

Academic Editors: Simone Salvadori, Daniela Anna Misul and

Mauro Carnevale

Received: 26 October 2021

Accepted: 29 November 2021

Published: 10 December 2021

Publisher's Note: MDPI stays neutral with regard to jurisdictional claims in published maps and institutional affiliations.

Copyright: (c) 2021 by the authors. Licensee MDPI, Basel, Switzerland. This article is an open access article distributed under the terms and conditions of the Creative Commons Attribution (CC BY) license (https:// creativecommons.org/licenses/by/ $4.0 /)$.

\begin{abstract}
With the incremental power of construction machinery diesel engines, the power performance of diesel engines and the pollutant emissions from the exhaust gas have imposed increasingly stringent requirements on the intake cooling system of diesel engines. This paper compared the $j / f$ evaluation factors for fin unit bodies of water-cooled intercooler (including straight fins and rectangular misaligned fins) by means of CFD simulation, and found that the rectangular misaligned fins had an $8 \%$ advantage in comprehensive performance. With the rectangular staggered fin intercooler, it was found that under the same conditions, the cooling efficiency of the dual-pass water-cooled intercooler is higher than that of the single-pass water-cooled intercooler, and the uniformity factor of the temperature difference field of the dual-pass water-cooled intercooler is $1.5 \%$ higher than that of the latter. The accuracy of the overall simulation of the intercooler is verified by the field test. The dual-pass and single-pass water-cooled intercooler both can maintain heat balance under working conditions, and its average air inlet temperature is $10^{\circ} \mathrm{C}$ lower than that of the original air-cooled intercooler, which provides support for further reducing the engine air inlet temperature. The results provide a theoretical basis for the performance improvement of water-cooled intercoolers.
\end{abstract}

Keywords: water-cooled intercooler; fin structure; CFD; construction machinery

\section{Introduction}

As an important part of internal combustion engine cooling systems, the intercooler improves power, reduces fuel consumption and reduces harmful emissions [1-3]. In the early stage, the research on flow and heat exchange of intercoolers was limited to experimental studies due to a lack of relevant technical support. In recent years, the methods of numerical simulation and data analysis have been widely used with the help of computer capabilities [4-6]. In order to meet the increasingly stringent emission regulations, a large number of scholars continue to develop and improve intercooler technology. At present, researchers have carried out a lot of in-depth research on intercooler design, simulation, optimization and other aspects.

Simulated calculation is also an important means to study the performance of coolers. At first, simulations were mainly two-dimensional due to the limitation of computer performance. Yuan Y. et al. [7] first conducted experiments, analyzed and processed the experimental data, and then simulation research was carried out. At that time, only two-dimensional numerical simulation research was carried out on the louver fin channel of the tube-belt intercooler due to the limitations of computer software and hardware. Then, the influence of different fins on the heat transfer performance and flow resistance characteristics were studied. The simulation calculations and experimental research were carried out. The comparison of results shows that the simulation results are accurate. Song R. et al. [8] used Fluent simulation software to perform numerical simulation calculations on the flow channel, and studied the heat transfer characteristics and resistance characteristics of the staggered fin. In order to ensure the predictive efficiency and accuracy of the 
staggered fin, the choices under different Reynolds numbers are different. Yang H. et al. [9] studied the heat transfer characteristics and flow resistance characteristics in the vertical channels of rectangular fins, zigzag fins and porous fins. The mechanism of the influence of heating conditions on the heat transfer performance of the cooler was discussed, and the Manglik and Bergles correlation was revised. Hao J.H. et al. [10] introduced the heat flow method into the design and optimization of the cooler structure, combined with the empirical relationship between heat transfer and flow resistance, and proposed a new solution method. Through this mathematical method, the fin structure can be optimized. $\mathrm{Li} \mathrm{K}$. et al. [11] used the experimental design method and the response surface method to study the influence of the geometric parameters of the zigzag fin of the plate-fin cooler on the heat dissipation resistance. The results show that the fin height, the length of the fin discontinuity and the fin spacing are positively correlated with the heat transfer coefficient, while the fin thickness is negatively correlated with the heat transfer coefficient. Richter Do Nascimento C. et al. [12] used an optimization technique to optimize the design of a counterflow plate-fin compact cooler with offset fins under different mass flow conditions. Li J. et al. $[13,14]$ conducted an experimental study on the boiling pressure drop characteristics of offset finned two-phase flow in a low-temperature compact heat exchanger. A new relationship for the prediction of frictional pressure drop was established, which was consistent with $95 \%$ of the experimental data within a deviation of $\pm 25 \%$. Kedam N. et al. [15] studied a unique heat transfer factor " $\mathrm{j}$ " and friction factor " $\mathrm{f}$ " model for offset strip fins and rectangular wavy fins, and considered the influence of geometric variables such as plate space $(\mathrm{Hp})$, fins Pitch $(\mathrm{Pf})$, hydraulic diameter $(\mathrm{Dh})$, wave amplitude $(\mathrm{Aa})$, fin length $(\lambda)$ and Reynolds number (Re). Based on RMSPE and experimental data analysis, the proposed $\mathrm{j}$ and $\mathrm{f}$ models were verified and are superior to the existing offset strip fin and rectangular wavy fin models. Achaichia, A. and Cowell, T. [16] also studied the heat transfer and flow performance of different size structures of the intercooler by numerical simulation.

In this paper, considering the lack of heat dissipation efficiency of the intercooler, multipass designs are adopted in the cooling side of the radiator to create the coolant, and high-temperature gas carries out more efficient heat transfer improving the heat transfer efficiency of the intercooler. This provides a new method for intercooler design.

\section{Governing Equation}

When studying the heat transfer and flow characteristics of the intercooler in the flow field, three conservation (1) laws are required: law of conservation of mass, law of conservation of momentum, and law of conservation of energy. The heat transfer of the intercooler in the flow field follows the Newtonian cooling formula. In this paper, the heat transfer of the intercooler is calculated by the efficient heat transfer element method [17] (2).

$$
\left\{\begin{array}{l}
\frac{\delta(\rho \varphi)}{\delta t}+\operatorname{div}(\rho \mu \varphi)=\operatorname{div}(\Gamma \operatorname{rgrad} \varphi)+s \\
\frac{\partial^{2} T}{\partial x^{2}}+\frac{\partial^{2} T}{\partial y^{2}}+\frac{\partial^{2} T}{\partial z^{2}}=0
\end{array}\right.
$$

where $s$ is the momentum source term, $\Gamma$ is the diffusion coefficient, $u$ is the velocity vector [17].

$$
\left\{\begin{array}{l}
\varepsilon=1-\frac{1}{\exp \left(\frac{N T U^{0.22}}{C r}\left(1-\exp \left(-C r \cdot N T U^{0.22}\right)\right)\right)} \\
Q=\varepsilon \cdot C \min (T h i-T c i)
\end{array}\right.
$$

where $\mathrm{Cr}$ is the heat capacity ratio, NTU is the number of heat transfer units.

The pressure loss caused by air flowing through the heat dissipation module and power cabin shall be calculated according to formula [17] (3).

$$
\left\{\begin{array}{l}
\Delta P=\frac{1}{2} \rho f_{p} U_{A \min }^{2} \\
f_{p}=\left(k+1-\delta^{2}\right)-\left(1-\delta^{2}-k_{e}\right) \frac{v_{e}}{v_{i}}+2\left(\frac{v_{\varepsilon}}{v_{i}}-1\right)+\alpha R_{e}^{b} \frac{A}{A_{c}} \frac{v_{u}}{v_{i}}
\end{array}\right.
$$


where $f_{p}$ is the pressure loss coefficient, $\rho$ is the air density, $U_{A \text { min }}$ is the flow velocity of the minimum flow area, $\alpha$ is the friction coefficient, $b$ is the friction index.

As a type of compact heat exchanger, the intercooler is evaluated based on the overall heat transfer performance on the macro level and the performance of the fin unit inside the intercooler on the micro level. The intercooler studied in this paper is a plate-fin heat exchanger. The waterside and airside fins use rectangular staggered fins. The comprehensive performance of the fins is evaluated by the $j / f$ comprehensive factor (6) method. The $j / f$ comprehensive factor evaluation method, which is a fin evaluation factor based on the ratio of Colburn heat transfer factor and Fanning friction factor, is proposed. Because the performance parameters of unreinforced fins are introduced in the formula, the $j / f$ evaluation factor is more objective than the $j / f$ factor ratio method proposed by Kays and London [18]. In Equation (6), the variable with $R$ angle mark represents the friction factor and heat transfer factor of the unreinforced fin. In this paper, the straight fin is selected as the unreinforced fin.

$$
\begin{gathered}
j=\frac{N u \cdot \operatorname{Pr}^{-1 / 3}}{\operatorname{Re}} \\
f=\frac{\Delta p D_{e}}{4 l} / \frac{\rho u_{m}^{2}}{2} \\
j / f=\frac{j / j_{R}}{\left(f / f_{R}\right)^{1 / 3}}
\end{gathered}
$$

where $j$ is the heat transfer factor, $f$ is the friction factor, $N u$ is the Nusselt coefficient, $\operatorname{Pr}$ is the Prandtl number, $R e$ is the Reynolds number, $D e$ is the equivalent diameter, $u_{m}$ is the average speed.

\section{Performance Analysis of Water-Cooled Intercooler Unit}

The plate-fin-type water-cooled intercooler is composed of several layers of water-side heat sinks and air-side heat sinks. Each layer of the heat sink is filled with fins to enhance heat dissipation. It is difficult to simulate the whole model of the intercooler with the current computer performance, so at present, researchers mainly use the porous medium method that takes a fin with the characteristic length direction of the radiator as the unit to carry out CFD simulation of the radiator model [19]. In preprocessing, periodic and symmetrical boundaries are set to maximize the actual radiator characteristics The pressure drop and heat transfer parameters of the unit at different inlet velocities obtained from the calculation of the flow field are simulated in the form of Equation (7) [20], and then two key coefficients of porous media are obtained: viscous resistance coefficient $a^{-1}$ and inertial resistance coefficient $C_{2}$.

$$
\frac{\Delta P}{\Delta n}=C_{2} \frac{1}{2} \rho v^{2}+\frac{1}{\alpha} \mu \nu
$$

The waterside and airside fins of the water-cooled intercooler studied in this paper are rectangular staggered fins with a fin thickness of $0.2 \mathrm{~mm}$. The structural parameters of the two fins are shown in Table 1 . The core part of the intercooler is made of brazing with a size of $300 \mathrm{~mm} \times 120 \mathrm{~mm} \times 110 \mathrm{~mm}$ [20].

Table 1. Structural parameters of water-cooled charge air cooler.

\begin{tabular}{cccccc}
\hline & Number of Plies & Fin Height & Heat Transfer Area & Fin Thickness & Tooth Angle \\
\hline Airside & 10 & $6.5 \mathrm{~mm}$ & $2.06 \mathrm{~m}^{2}$ & $0.2 \mathrm{~mm}$ & $90^{\circ}$ \\
Waterside & 9 & $3 \mathrm{~mm}$ & $1.37 \mathrm{~m}^{2}$ & $0.2 \mathrm{~mm}$ & $90^{\circ}$ \\
\hline
\end{tabular}

The charge air-side unit body model established based on the above data is shown in Figure 1. The model inlet is set as the velocity inlet and the outlet is set as the pressure outlet, and the intake speed is $2 \sim 20 \mathrm{~m} / \mathrm{s}$, respectively, with an increment of $2 \mathrm{~m} / \mathrm{s}$. 


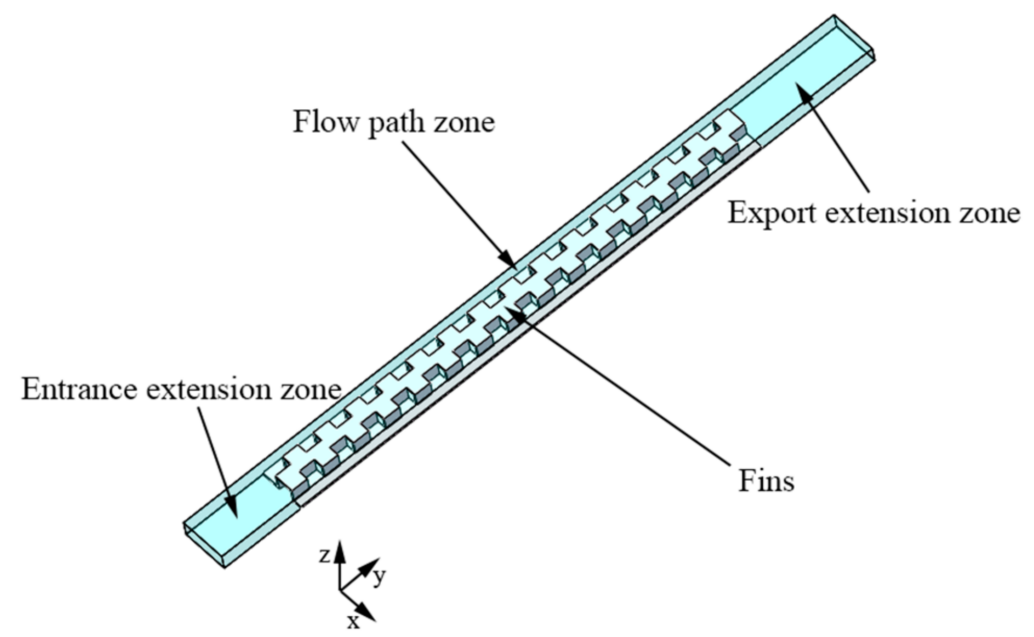

Figure 1. The airside unit model.

The simulation results are fitted to the velocity pressure drop curve as shown in Figure 2.

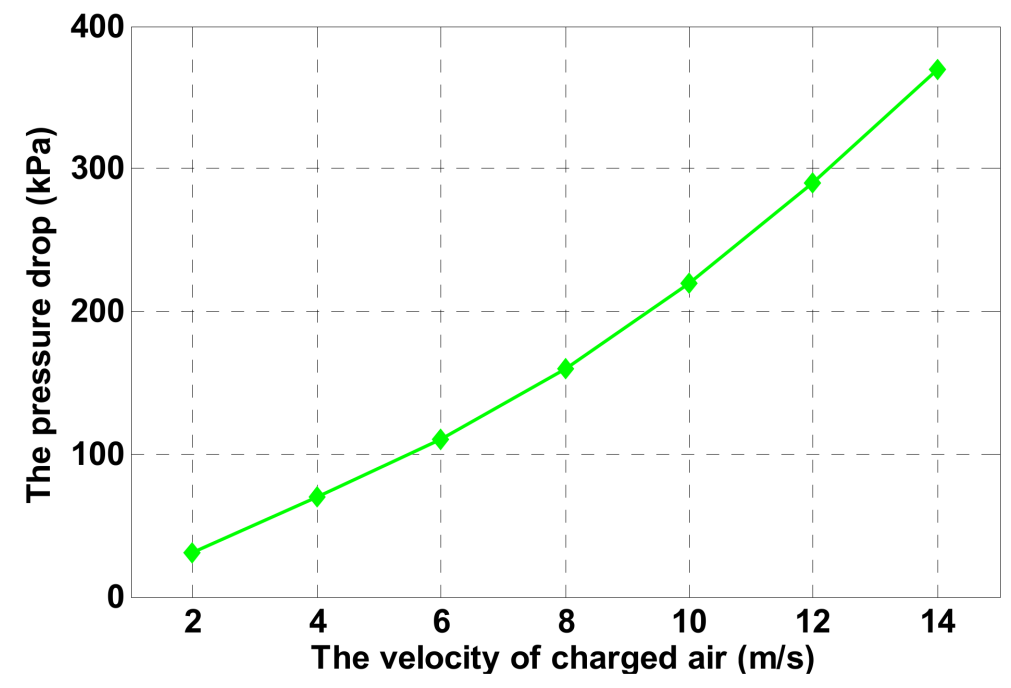

Figure 2. Curve of airside unit velocity pressure drop.

The $j / f$ evaluation factor curve is drawn by taking the simulation data of rectangular staggered fin unit into Equations (4)-(6). The simulation data of flat and straight fins of the same size are introduced to compare the $j / f$ evaluation factors with rectangular staggered fins (Figure 3). With the increase in air velocity, the pressure drop of rectangular staggered fins will be on the increase and the growth rate will increase, but the increase in the convective heat transfer coefficient will slow down, which results in the rapid increase in $j / f$ evaluation factor in the low Reynolds number stage and the relatively gentle increasing trend in the high Reynolds number stage. The average $j / f$ factor of the rectangular staggered fin is $8 \%$ higher than that of the straight fin, but the advantage decreases with the increase in high Reynolds number. According to Equation (7), the parameters of the porous medium of the waterside fin and the airside fin can be calculated, as shown in Table 2. 


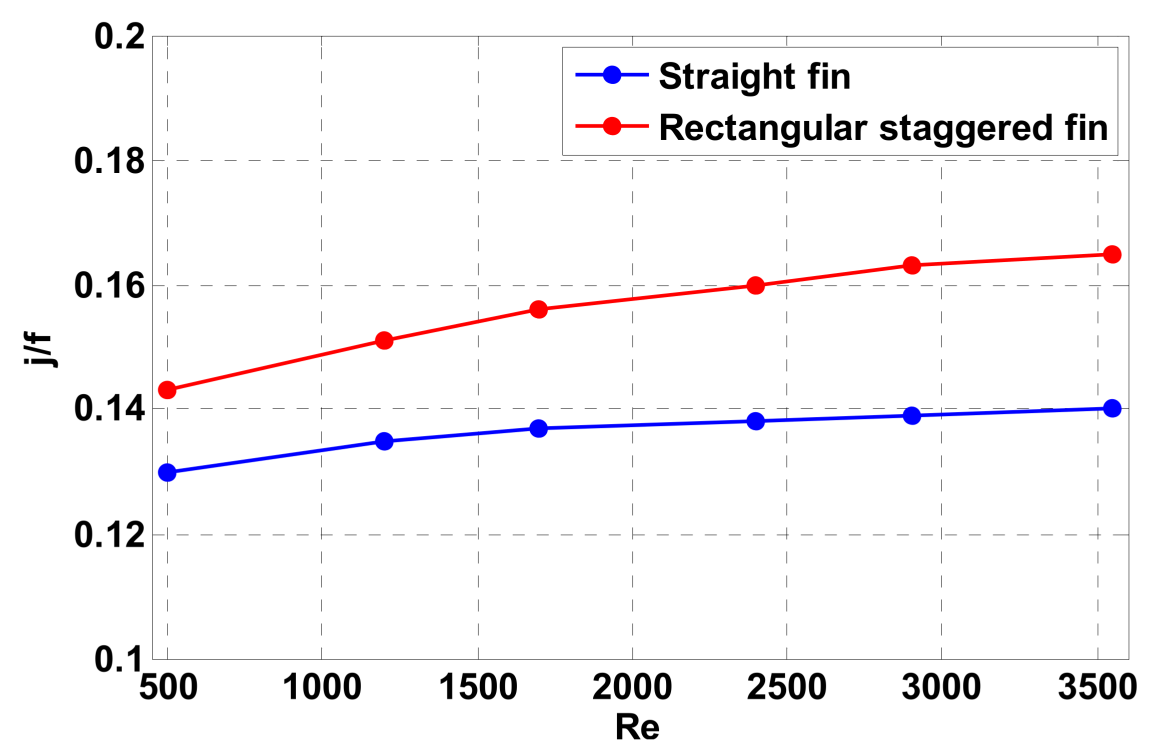

Figure 3. The curve of $j / f$ factor with Reynolds number.

Table 2. The porous medium of charge air cooler.

\begin{tabular}{|c|c|c|c|}
\hline & $\begin{array}{l}\text { Coefficient of Inertia Resistance } \\
\qquad C_{2} / 1 \cdot \mathrm{m}^{-1}\end{array}$ & $\begin{array}{l}\text { Viscous Drag Coefficient } \\
\qquad a^{-1 / 1 \cdot m^{-2}}\end{array}$ & Porosity \\
\hline The airside & 10 & $8.15 \times 10^{7}$ & 0.91 \\
\hline The waterside & 67 & $2.84 \times 10^{7}$ & 0.93 \\
\hline
\end{tabular}

\section{Overall Performance Analysis of Water-Cooled Intercooler}

\subsection{Flow Field Analysis of Water-Cooled Intercooler}

According to the different requirements of specific engineering problems, the commonly used heat exchanger flow channel designs are divided into single-pass and multipass designs. The cooling water flow mode of the single-process water-cooled intercooler studied in this paper is four-times the cross flow, and the unidirectional flow of hot and cold fluid is shown in Figure 4. The dual-flow water-cooled intercooler is composed of two layers of four crossflow radiators in series. The difference is that the second flow of cold and hot fluid flows in the opposite direction, as shown in Figure 5. The two resistance coefficients of the rectangular staggered fins have been obtained above, and the porous media model is used to simulate the fluent steady-state flow field of the single and double flow intercoolers. The flow field simulation of the intercooler is different to that of the common heat exchanger. Because the air in the air inlet is compressed, the physical parameters of the air cannot adopt the standard pressure parameters in the database provided by Fluent. The air temperature and pressure of the air inlet simulated in this paper are $120^{\circ} \mathrm{C}$ and $200 \mathrm{KPa}$, and the physical parameters are shown in Table 3. The ambient temperature in the power cabin is set as $40^{\circ} \mathrm{C}$, the air intake of the intercooler is $0.3 \mathrm{~kg} / \mathrm{s}$, the temperature of the cooling water is $40^{\circ} \mathrm{C}$, and the flow rate is $60 \mathrm{~L} / \mathrm{min}$. The turbulence model used SIMPLEC. The overall performance of the intercooler was simulated and the results were compared by Fluent. 


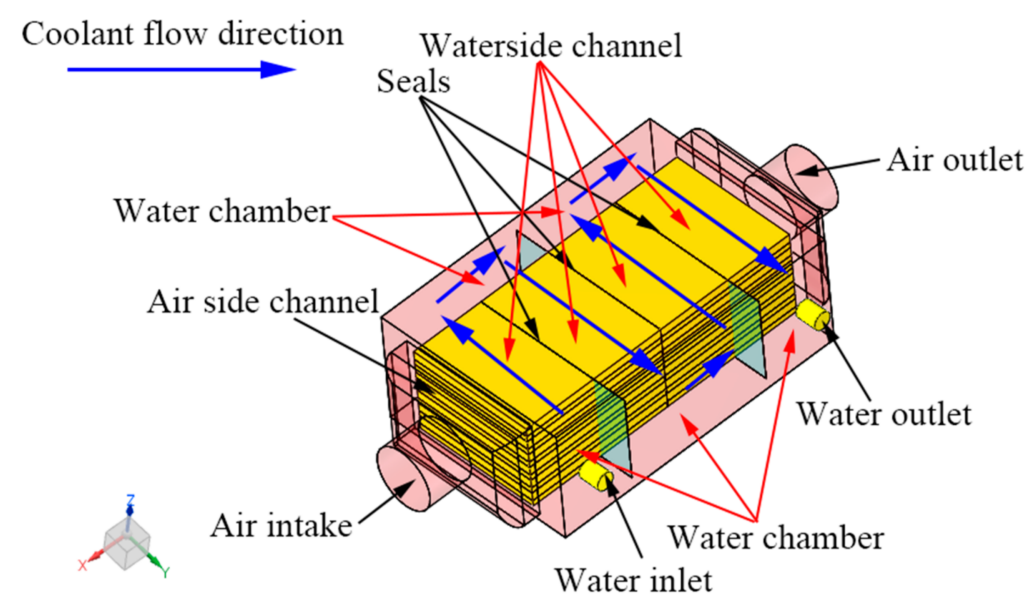

Figure 4. The single-pass water-cooled charge air cooler.

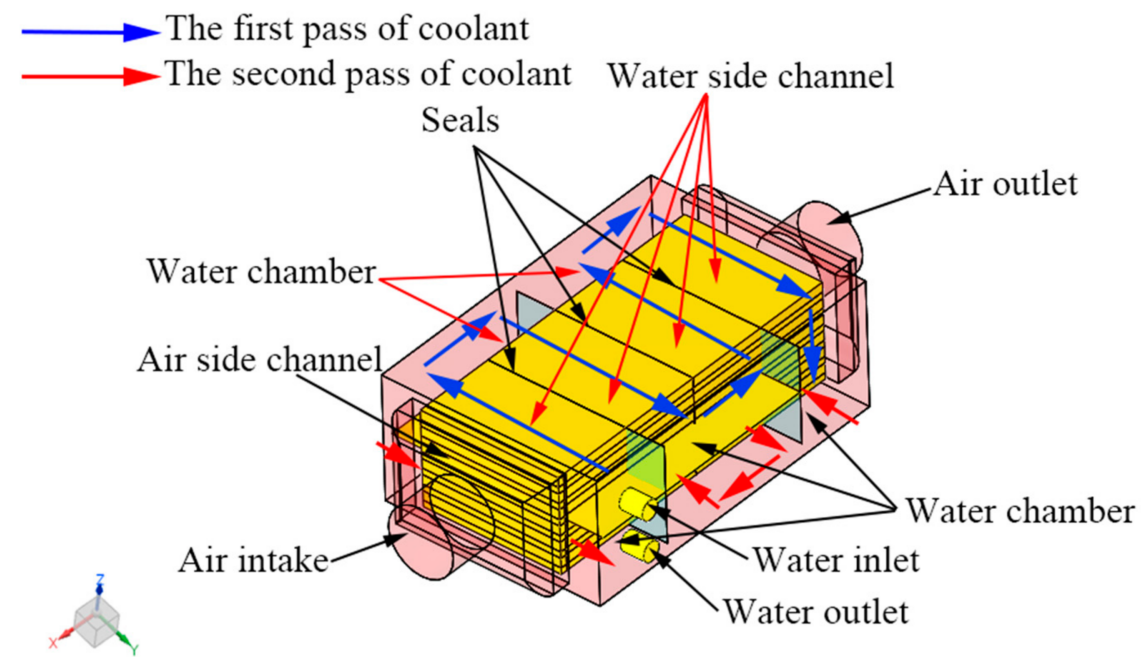

Figure 5. The dual-pass water-cooled charge air cooler.

Table 3. Physical parameters of pressurized air.

\begin{tabular}{cccc}
\hline Density kg/m $\mathbf{m}^{3}$ & $\begin{array}{c}\text { Constant Pressure Specific } \\
\text { Heat Capacity J/(kg.K) }\end{array}$ & $\begin{array}{c}\text { Thermal Conductivity } \\
\mathbf{W} /(\mathbf{m} \cdot \mathbf{k})\end{array}$ & Dynamic Viscosity Pa.s \\
\hline 2.656 & 1015 & $32.54 \times 10^{-3}$ & $22.83 \times 10^{-6}$ \\
\hline
\end{tabular}

As shown in Figures 6 and 7, the temperature profiles of the central section (XY plane) of the cooler height direction in the single-pass and dual-pass are compared. After the flow heat exchange of the two processes, the temperature of the air outlet of the dual-pass intercooler is lower than that of the single-pass intercooler. The cooling water flows into the intermediate water chamber after passing the first process, and then flows from the intermediate water chamber to the second process to continue the heat exchange with the pressurized air, and finally flows out of the intercooler from the water outlet. The cooling water of the single-pass intercooler flows in a U-shape, directly through baffles, and there is only one flow path for heat exchange between it and pressurized air. However, compared with the double-flow intercooler, the single-flow intercooler has the advantage of pressure drop. Due to the particularity of its structure, the length of its internal cooling water flow channel is doubled, resulting in the cooling water flow rate in its channel being twice that of the single flow, which directly leads to a significant increase in the resistance along the waterside. Therefore, in order to overcome the excessively high waterside pressure drop of the cooler in the dual process, a pump with a larger head is required. There is no 
obvious difference in the pressure drop on the airside because the structure of the airside heat sink and the fin is the same. Compared with the data for each section extracted by surface weighting, the dual-pass intercooler is $7.5 \%$ more than the single-pass intercooler in heat transfer capacity, the temperature drop on the gas side is $4.5^{\circ} \mathrm{C}$ higher and the water pressure drop is $24.8 \%$ higher than that in the single-pass intercooler. The overall steady state simulation results of the intercooler are shown in Table 4.

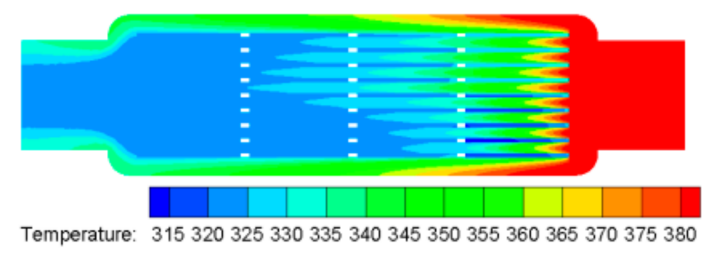

Figure 6. XY plane contours of two-pass water-cooled charge air cooler (K).

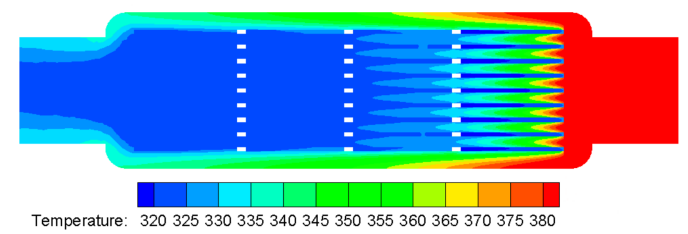

Figure 7. XY plane contours of single-pass water-cooled charge air cooler (K).

Table 4. Simulation results of the charge air cooler.

\begin{tabular}{ccccc}
\hline & $\begin{array}{c}\text { Waterside } \\
\text { Pressure Drop }\end{array}$ & $\begin{array}{c}\text { Airside Temperature } \\
\text { Drop }\end{array}$ & $\begin{array}{c}\text { Waterside } \\
\text { Temperature Rise }\end{array}$ & $\begin{array}{c}\text { Heat Exchange } \\
\text { Capacity }\end{array}$ \\
\hline The dual-pass & $12.51 \mathrm{kPa}$ & $70.6^{\circ} \mathrm{C}$ & $5.5^{\circ} \mathrm{C}$ & $21.5 \mathrm{~kW}$ \\
The single-pass & $10.02 \mathrm{kPa}$ & $66.1^{\circ} \mathrm{C}$ & $4.9^{\circ} \mathrm{C}$ & $20.1 \mathrm{~kW}$ \\
\hline
\end{tabular}

4.2. Analysis of Temperature Field Uniformity of Water-Cooled Intercooler

$$
\begin{gathered}
\theta(x, y, z)=T_{\text {hot }}(x, y, z)-T_{\text {cold }}(x, y, z) \\
\Phi=\frac{\sum_{i=1}^{N} \sum_{j=1}^{M}\left[T_{\text {hot }}(i, j)-T_{\text {cold }}(i, j)\right]}{\sqrt{M N \sum_{i=1}^{N} \sum_{j=1}^{M}\left[T_{\text {hot }}(i, j)-T_{\text {cold }}(i, j)\right]^{2}}}
\end{gathered}
$$

The uniformity of the temperature field distribution directly affects the heat transfer efficiency of the radiator and is an important index for evaluating the performance of the radiator. The field synergy principle is used to study the uniformity of the temperature field, and the difference is used as the uniformity factor to evaluate the uniformity of temperature distribution [21]. Field synergy principle was proposed by academic Guo Z.Y, who proposed the theory of temperature difference field uniformity by comparing the efficiency of the upstream and downstream heat exchangers. According to the field synergy principle, the three-dimensional heat exchanger body is simplified by two-dimensional projection, which is especially suitable for the plate fin heat exchanger with a symmetrical core structure. First of all, the layer of heat sink is divided into an $\mathrm{M} \times \mathrm{N}$ matrix by means of dividing each layer of the heat sink into several small areas. Then, the weighted average value of each unit is extracted to digitize the heat sink. In addition, the two-dimensional simplification of the radiator is completed by projecting the extracted data of several layers 
on the warm side and the cold side to a single surface. Finally, the temperature fields of the hot side and the cold side of the heat exchangers are established.

By comparing Figures 8 and 9, it is found that the high-temperature part of the single-pass water-cooled intercooler is mainly concentrated within $120 \mathrm{~mm}$ in the length direction, and the second half of the intercooler has a lower temperature and less heat transfer. The difference between the high and low temperature is about $20{ }^{\circ} \mathrm{C}$, and the temperature field is unevenly distributed. The dual-pass heat exchanger has two processes to make the cooling fluid more uniform. By observing the airside temperature field, it is found that the uneven distribution is mainly concentrated near the upper and lower water chambers, which conforms to the heat transfer law. The high-temperature part of the dual-pass intercooler is concentrated within $250 \mathrm{~mm}$ in the width direction, which indicates that most of the volume in the intercooler is involved in heat exchange to make the heat exchange more efficient, and the temperature field distribution is uniform compared to the single-pass intercooler. The waterside temperature field distribution of single-pass and double-pass intercoolers can be established according to the same method, and the temperature difference field distribution of waterside intercoolers can be obtained by using the difference between the waterside temperature field and the gas-side temperature field. According to Equations (9) and (10) [22], the uniformity factor of temperature field is calculated. The uniformity factor of the temperature field of the single-pass intercooler is 0.975 , and that of the dual-pass intercooler is 0.989 . The uniformity of the temperature difference field in the dual-pass is higher than that in the single-pass, so the heat exchange effect of the dual-pass intercooler is better than that of the single-pass intercooler. The uniformity of the temperature difference field of the dual-pass intercooler is higher than that of the single-pass radiator, therefore the heat transfer effect of the dual-pass intercooler is better than that of the single-pass intercooler.

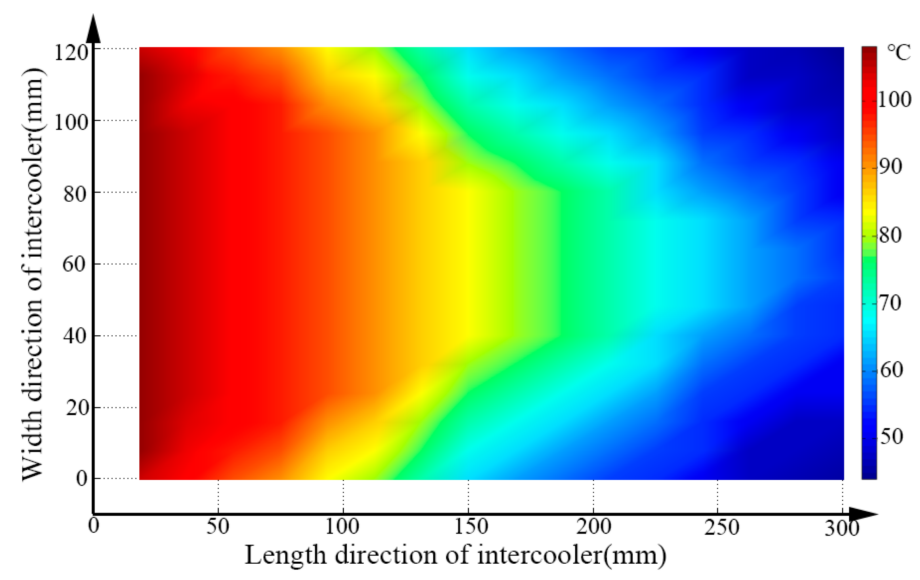

Figure 8. Airside temperature field of single-pass water-cooled charge air cooler.

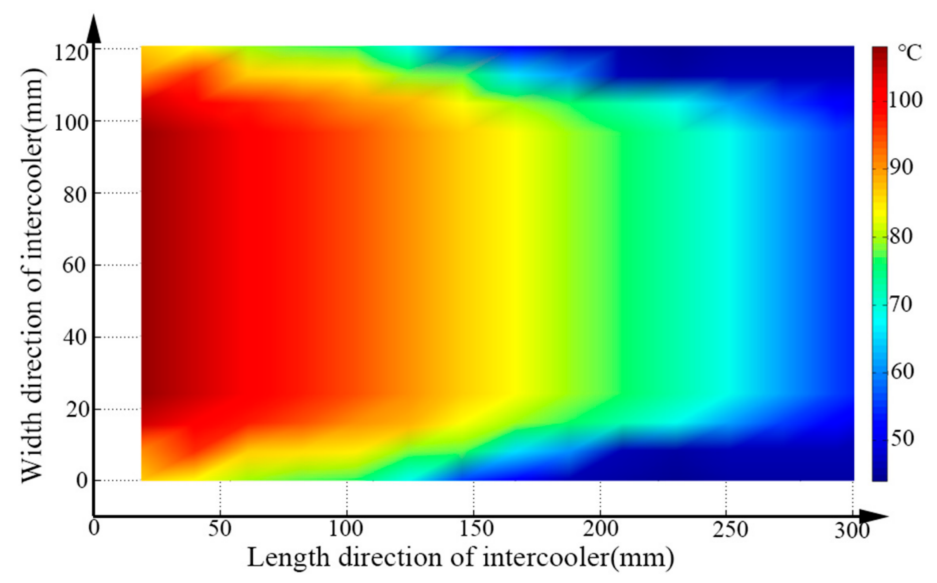

Figure 9. Airside temperature field of two-pass water-cooled charge air cooler. 


\section{Comparative Analysis of Experiments}

The flow-field performance and temperature-field uniformity of single-process and double-process water-cooled intercoolers have been studied above. According to the results of steady-state simulation, the heat exchange capacity of single-pass or dual-pass intercoolers is higher than that of original air-cooled intercoolers under the same air intake amount.

To verify the results of CFD, a certain transporter used in the test, the air intake capacity at the rated power is about $0.33 \mathrm{~kg} / \mathrm{s}$. Field experimental data were recorded using DEWE and Krypton data collectors from DEWE soft with a sampling frequency of $100 \mathrm{~Hz}$. The test condition is high-speed running. Omitting the heat engine time period, a 55 second-long winding cycle is intercepted from $1493.3 \mathrm{~s}$, and a 55 second-long continuous lifting cycle is intercepted from $3769.2 \mathrm{~s}$. The data of each cycle are compared, as shown in Figure 10.

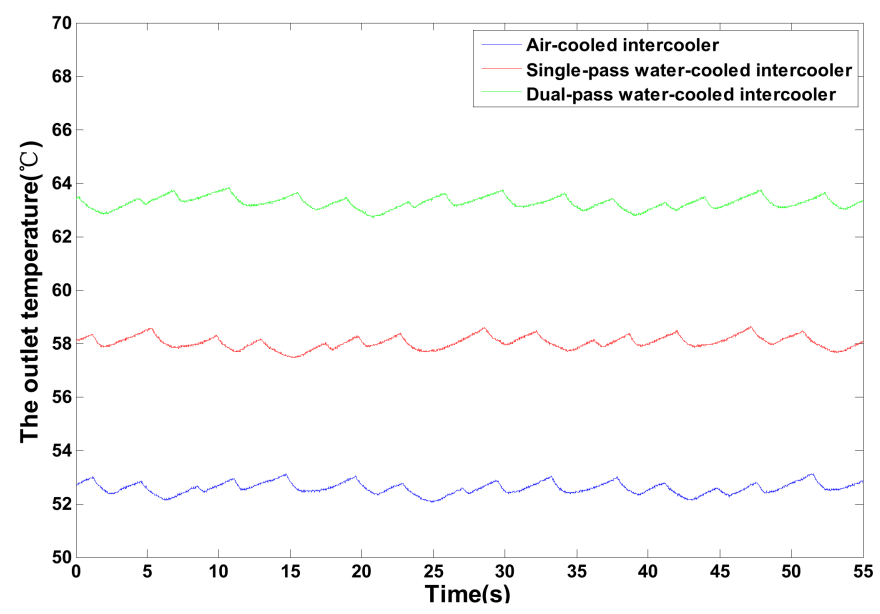

Figure 10. Comparison of charge air temperatures under high-speed running condition.

Under high-speed running, the temperature of the charge air outlet in the air-cooled intercooler continues to rise, because the heat exchange capacity of the air-cooled intercooler has reached a bottleneck and cannot meet the cooling demand of the charge air. The outlet temperature of the pressurized air in the water-cooled intercooler is significantly lower than that of the air-cooled intercooler and maintains a thermal equilibrium state, which indicates that the air-cooled intercooler can no longer meet the cooling demand under a high temperature and heavy load environment, while the water-cooled intercooler can meet the cooling demand. When the intake air temperature rises, the water-cooled intercooler can increase the heat exchange capacity by changing the flow rate of the water pump, while the air-cooled intercooler needs to adjust the speed of the cooling fan to improve the heat dissipation capacity. The latter has a longer response time and tends to cause a brief overheating of the engine.

The thermal equilibrium temperatures during working conditions is shown in Table 5. There is a significant difference between the test value and the simulation value, but the overall deviation is less than $10 \%$. Although the intake air temperature of water-cooled and air-cooled intercoolers are within the normal range under both operating conditions, the heat-exchange performance of water-cooled intercoolers is better because the average outlet temperature of pressurized air of water-cooled intercoolers is about $10^{\circ} \mathrm{C}$ lower than that of air-cooled intercoolers. If a transporter equipped with a two-process water-cooled intercooler is used for the test, the intake air temperature can be controlled to within $50 \mathrm{C}$, which will greatly reduce the NOx and soot emissions of the engine and improve the engine power performance to a certain extent [23]. 
Table 5. Core volume comparison of charge air cooler.

\begin{tabular}{ccc}
\hline & \multicolumn{2}{c}{ Average Temperature } \\
\cline { 2 - 3 } & CFD & High Speed \\
\hline Air-cooled intercooler & 66.3 & 65.7 \\
Single-pass water cooling & 53.9 & 52.4 \\
Dual-pass water cooling & 49.4 & 51.7 \\
\hline
\end{tabular}

\section{Conclusions}

The $j / f$ evaluation factors were used to analyze rectangular staggered fins and straight fins. The performance gap between the air-cooled intercooler and water-cooled intercooler increased as the Reynolds number increased, and the average performance gap reached $8 \%$. The uniformity of the temperature field distribution is introduced to analyze the singlepass water-cooled intercooler and the dual-pass water-cooled intercooler. Comparing the two field-cooler temperature difference field uniformity factors, it was found that the dual-process water-cooled intercooler has a $1.5 \%$ advantage in heat dissipation.

Author Contributions: Conceptualization, C.Y.; methodology, C.Y.; software, X.X.; validation, J.L.; formal analysis, G.L.; investigation, X.X.; resources, W.Z.; data curation, W.Z.; writing—original draft preparation, C.Y.; writing—review and editing, C.Y.; visualization, J.L.; supervision, X.X.; project administration, X.X.; funding acquisition, X.X. All authors have read and agreed to the published version of the manuscript.

Funding: This research received no external funding.

Institutional Review Board Statement: Not applicable.

Informed Consent Statement: Not applicable.

Data Availability Statement: Not applicable.

Conflicts of Interest: The authors declare no conflict of interest.

\section{Nomenclature}

$\begin{array}{ll}j & \text { Colburn factor } \\ f & \text { Friction factor } \\ T & \text { Temperature }(\mathrm{K}) \\ D & \text { Hydraulic diameter }(\mathrm{m}) \\ \Delta P & \text { Pressure difference }(\mathrm{Pa}) \\ f_{p} & \text { Pressure loss coefficient } \\ m & \text { Mass flow }(\mathrm{kg} / \mathrm{s}) \\ c_{p} & \text { Constant-pressures pecific heat }\left(\mathrm{J} /\left(\mathrm{kg}^{\circ} \mathrm{C}\right)\right) \\ k & \text { Heat transfer coefficient } \\ R e & \text { Reynolds number } \\ P r & \text { Prandtl number } \\ N u & \text { Nusselt number } \\ D e & \text { Equivalent diameter } \\ \rho & \text { Density }\left(\mathrm{kg} / \mathrm{m}^{3}\right) \\ \mu & \text { Dynamic viscosity }\left(\mathrm{N} \cdot \mathrm{s} / \mathrm{m}^{2}\right) \\ \lambda & \text { Thermal conductivity }\left(\mathrm{W} /\left(\mathrm{m}^{\circ} \mathrm{C}\right)\right) \\ \sigma & \text { Variance of basis function } \\ \Gamma & \text { Diffusion coefficient } \\ u & \text { Velocity } \\ C_{r} & \text { Heat capacity ratio } \\ N T U & \text { Number of heat transfer units } \\ U_{A m i n} & \text { Flow velocity of the minimum flow area }\end{array}$




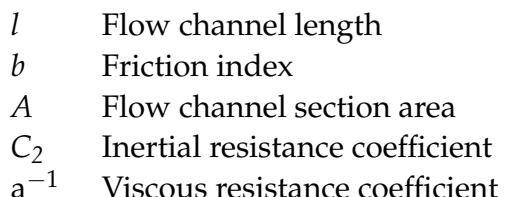

\section{References}

1. Chi, C.W.; Kuan, Y.C. Heat Transfers and Friction Characteristics of Plain Fin and Tube Heat Exchangers, Part I: New Exchangers in Wet Conditions. Heat Mass Transf. 2000, 43, 3443-3452.

2. Cristian, C.; Danielle, M.; Philippe, N. Thermo-hydraulic Characterization of An Automotive Intercooler for a Low Pressure EGR Application. Appl. Therm. Eng. 2011, 31, 2474-2484.

3. Dong, W.; Wen, C.-Z.; Zheng, P.Y. Numerical Simulation of Intercooler Flow Path for Marine Gas Turbine. J. Aerosp. Power 2010, 25, 636-640.

4. Ying, Y.L.; Cao, Y.P.; Li, S.Y. Study on Flow Parameters Optimisation for Marine Gas Turbine Intercooler System Based on Simulation Experiment. Int. J. Comput. Appl. Technol. 2013, 47, 56. [CrossRef]

5. Wen, C.Z.; Dong, W. Numerical Simulation of Heat Transfer and Fluid Flow on Marine Gas Turbine Intercooler. J. Aerosp. Power 2010, 25, 654-658.

6. Wu, H.; Dai, X.; Zhang, Y. Research of Intercooler Heat Transfer Based on CFD. In Proceedings of the 13th International Conference on Emerging Learning Technologies and Applications, High Tatras, Slovakia, 26-27 November 2015.

7. Yuan, Y.; Jackson, A.; Nelson, M. CFD Simulation of Flow and Heat Transfer in Airways. Sae Tech. Pap. 2001, 1, 68-72.

8. Song, R.; Cui, M. Single- and multi-objective optimization of a plate-fin heat exchanger with offset strip fins adopting the genetic algorithm. Appl. Therm. Eng. 2019, 159, 113881. [CrossRef]

9. Yang, H.; Li, Y.; Yang, Y.; Zhu, Y.; Wen, J. Effect of surface efficiency on the thermal design of plate-fin heat exchangers with passages stack arrangement. Int. J. Heat Mass Transf. 2019, 143, 118494. [CrossRef]

10. Hao, J.H.; Chen, Q.; Ren, J.X.; Zhang, M.-Q.; Ai, J. An experimental study on the offset-strip fin geometry optimization of a plate-fin heat exchanger based on the heat current model. Appl. Therm. Eng. 2019, 154, 111-119. [CrossRef]

11. Li, K.; Wen, J.; Liu, Y.; Liu, H. Application of entransy theory on structure optimization of serrated fin in plate-fin heat exchanger. Appl. Therm. Eng. 2020, 173, 114809. [CrossRef]

12. Richter Do Nascimento, C.A.; Mariani, V.C.; Coelho, L.D.S. Integrative numerical modeling and thermodynamic optimal design of counter-flow plate-fin heat exchanger applying neural networks. Int. J. Heat Mass Transf. 2020, 159, 120097. [CrossRef]

13. Li, J.; Hu, H.; Zhang, Y. Experimental investigation and correlation development for two-phase pressure drop characteristics of flow boiling in offset strip fin channels. Int. J. Therm. Sci. 2021, 160, 106693. [CrossRef]

14. $\mathrm{Hu}, \mathrm{H}$.; Li, J. Experimental investigation on heat transfer characteristics of two-phase flow boiling in offset strip fin channels of plate-fin heat exchangers. Appl. Therm. Eng. 2021, 185, 116404. [CrossRef]

15. Kedam, N. Heat transfer factor $\mathrm{j}$ and friction factor $\mathrm{f}$ correlations for offset strip fin and wavy fin of compact plate-fin heatexchangers. Case Stud. Therm. Eng. 2021, 28, 101552. [CrossRef]

16. Achaichia, A.; Cowell, T.A. Heat Transfer and Pressure Drop Characteristics of Flat Tube and Louvered Plate Fin Surfaces. Exp. Therm. Fluid Sci. 1988, 1, 147-157. [CrossRef]

17. Connect, P.; Learn, S. Heat and Mass Transfer: Fundamentals and Applications. Bus. Econ. 2014, 15, 774.

18. Kays, W.M.; London, A.L. Compact Heat Exchangers; McGraw-Hill: New York, NY, USA, 1984.

19. Yang, L.; Sicheng, Q. The optimization design of off-highway machinery radiator based on genetic algorithm and e-NTU. Acta Tech. Csav 2017, 62, 465-476.

20. Yu, C.; Xue, X.; Shi, K.; Shao, M.; Liu, Y. Comparative Study on CFD Turbulence Models for the Flow Field in Air Cooled Radiator. Processes 2020, 8, 1687. [CrossRef]

21. Thulukkanam, K. Heat Exchanger Design Handbook, 2nd ed.; CRC Press: Boca Raton, FL, USA, 2013.

22. Tao, W.Q.; Guo, Z.Y.; Wang, B.X. Field Synergy Principle for Enhancing Convective Heat transfer-its Extension and Numerical Verifications. Int. J. Heat Mass Transf. 2002, 45, 3849-3856. [CrossRef]

23. Lin, W.; Sunden, B. Vehicle Cooling Systems for Reducing Fuel Consumption and Carbon Dioxide: Literature Survey. Int. Powertrains Fuels Lubr. Meet. 2010, 22. [CrossRef] 